\title{
Review of Animal Models to Study Pulp Inflammation
}

\author{
Davy Aubeux 1,2,3, Emmanuelle Renard ${ }^{1,2,3}$, Fabienne Pérez ${ }^{1,2,3}$, Solène Tessier ${ }^{1,2}$, \\ Valérie Geoffroy ${ }^{1,2}$ and Alexis Gaudin ${ }^{1,2,3 *}$ \\ 1 Inserm, UMR 1229, RMeS, Regenerative Medicine and Skeleton, Université de Nantes, École nationale vétérinaire, \\ agroalimentaire et de l'alimentation de Nantes Atlantique (ONIRIS), Nantes, France, ${ }^{2}$ Unité Formation Recherche (UFR) \\ Odontologie, Université de Nantes, Nantes, France, ${ }^{3}$ Pôle Hospitalo-Universitaire 4 Ostéo-Articulaire - Tête et Cou - \\ Odontologie - Neurochirurgie - Neuro-Traumatologie - Uca (PHU4 OTONN), Centre Hospitalo-Universitaire (CHU) Nantes, \\ Nantes, France
}

\section{OPEN ACCESS}

Edited by: Ikhlas El karim, Queen's University Belfast, United Kingdom

Reviewed by:

Motoki Okamoto, Osaka University, Japan Naoto Ohkura

Niigata University, Japan

*Correspondence: Alexis Gaudin alexis.gaudin@univ-nantes.fr

Specialty section: This article was submitted to Endodontics,

a section of the journal Frontiers in Dental Medicine

Received: 27 February 2021 Accepted: 08 April 2021 Published: 05 May 2021

Citation:

Aubeux D, Renard E, Pérez F Tessier S, Geoffroy $V$ and Gaudin A (2021) Review of Animal Models to

Study Pulp Inflammation.

Front. Dent. Med. 2:673552. doi: 10.3389/fdmed.2021.673552
Human dental pulp is a highly dynamic tissue equipped with a network of resident immunocompetent cells that play a major role in the defense against pathogens and during tissue injury. Animal studies are mandatory and complementary to in vitro experiments when studying the physiopathology of dental pulp, new diagnostic tools, or innovative therapeutic strategies. This animal approach makes it possible to define a benefit-risk ratio necessary to be subsequently tested in humans. Among the animal kingdom, rodents, rabbits, ferrets, swine, dogs, and non-human primates have been used to model human pulpitis. The diversity of animals found in studies indicate the difficulty of choosing the correct and most efficient model. Each animal model has its own characteristics that may be advantageous or limiting, according to the studied parameters. These elements have to be considered in preclinical studies. This article aims to provide a thorough understanding of the different animal models used to study pulp inflammation. This may help to find the most pertinent or appropriate animal model depending on the hypothesis investigated and the expected results.

Keywords: pulpitis, animal research, animal models, lipopolysaccharide, dental pulp

\section{INTRODUCTION}

Dental pulp is a unique connective tissue encapsulated within mineralized hard structures (enamel and dentin). It is fit with a neurovascular network that permits to orchestrate the inflammatory reaction in case of injuries or infection, such as dental caries, traumatism, or operative procedures. The inflammation of the dental pulp, called pulpitis, is characterized by a tightly regulated sequence of vascular and cellular events. Odontoblasts are specific cells of the dental pulp. Due to their peripheral location, they are the first cells in contact with bacteria or their toxins. Their immunocompetent properties make them able to activate the inflammatory innate response (1-3). Indeed, odontoblasts have been shown to secrete inflammatory molecules, including chemokines and cytokines such as IL-6, IL-8, IL-10, CXCL1, CXCL2, CXCL8 (IL-8), CXCL10, and CCL2 (4, 5). These molecules activate immune cells recruitment from the vasculature to the site of inflammation (T- and B-lymphocytes, neutrophils, monocytes, and macrophages) $(3,6)$. Neutrophils migrate to the inflamed tissue and recruit inflammatory monocytes that potentiate the pro-inflammatory response (7).

Besides their immunocompetent properties, odontoblasts are able to synthesize tertiary (reactionary or reparative) dentin to protect the underlying pulp. Reactionary dentin is produced in the case of a moderate aggression, without destruction of the odontoblastic layer. In the case of 
a greater aggression, blood stasis and tissue hypoxia lead to the destruction of the odontoblastic palisade and death of odontoblasts. Odontoblasts are terminal differentiating cells which give rise to two cells during last mitosis; one which migrates toward the odontoblasts palisade to form an odontoblast and another one which migrates toward the Höhl layer to be stored there. This layer has long been considered as a potential reservoir of cells capable of engaging in a scar process during tertiary dentinogenesis (8). Other progenitor cells in the dental pulp, including dental pulp stem cells (9, 10), dental pulp pericytes (11) or smooth muscle actin-positive $(\mathrm{SMA}+)$ progenitors (12) may be recruited to the injury site and differentiate into odontoblast-like cells to eventually repair all or part of the damaged areas. Their location and recruitment mechanism are still hypothetical (13). However, the authors remain cautious about the capacity of these cells to produce real dentin because the studies carried out showed that the synthesized tissue was closer to bone tissue than to dentin tissue (osteodentin) $(14,15)$. Osteodentin is characterized by lacunar bone-like tissue and is histologically considered as immature mineralized tissue (16).

As in many diseases, when the host's aggression or defense response are excessive or uncontrolled, the pulp can engage in more deleterious pathways such as chronic inflammation, scarring, fibrosis up to pulp necrosis (17). Until recently, the potential positive effect of inflammation in pulpal healing has been underestimated and has been considered mainly as an undesirable side-effect. New evidence suggests that inflammation is an essential prerequisite for tissue healing and pulp regeneration, insofar as it can be controlled (18).

Management of inflammation is crucial when considering success for therapy aiming to preserve, maintain, or restore dental pulp in a healthy state namely "vital pulp therapies (VPT)." The removal of the pulp generates many disadvantages. Teeth may become more brittle, prone to fractures, and infection. The removal of the pulp prevents also the natural phenomena of healing and alarm signal from occurring. Thereby, the goal of such therapies is to limit tissue damage following injury and to control the inflammatory immune response to promote a return to homeostasis leading to pulp healing. Different strategies have been, are, and will be advocated to promote pulp healing, repair, or regeneration.

Regardless of the approach (molecules, drugs, and/or the use of drug delivery systems), any new research project or any new therapy requires in vitro studies to be carried out first (2D and $3 \mathrm{D}$ culture, organotypic culture). Then, in vivo studies are performed before clinical use in humans. In vitro experiments allow rapid assessment of the biological effects on cells and microorganisms in a reproducible way. However, these studies have many limitations. In vitro experiments are by definition performed outside the organism and are far from clinical applications. They do not recapitulate the complexity of the organism and the various interactions between cells and organ structure.

Despite the development of alternative methods (in silico computer models and simulations, isolated tissue/organ for tissue or organ bath system, databases) $(19,20)$, animal models are still mandatory and must be used for scientific purposes. In
2015, 192 million animals were used for scientific purposes (21). Historically, discovery of vaccines, pathologies, diagnostic tests, and therapeutic methods require the use of preclinical animal models, however the use of animal is still debated from an ethical point of view. In order to understand diseases, develop treatments, and test new ideas, concept, and technologies, researchers rely on animal models because of their scientific validity. In the case of the management of inflammation during pulpitis, it is important to have a reliable animal model of pulpitis to assess and evaluate the different therapeutic approaches that may be used for VPT.

\section{SPECIFICATIONS OF THE IDEAL ANIMAL MODEL OF PULPITIS}

The selection of the model or the animal species relies on the purpose and the methodology of the study. If there are no suitable alternatives to the use of animal models, then the appropriate species is selected on the basis of various scientific criteria (biological, anatomical, immune, and metabolic) and practical factors. Animal research is currently carried out on three main categories of animals: small animals (rats, mice, rabbits, ferrets, fish, and birds), large animals (dogs, cats, swine, and goats), and non-human primates.

Based on the previous observations, the specifications for the ideal animal model of pulpitis are $(22,23)$

- The animal model used must be as close as possible to humans from an anatomical, odontological, biological, and physiological point of view.

- The operating conditions for inducing pulpitis must be technically simple (accessibility, dental dam installation) and the inflammatory conditions obtained must be equivalent to that found in humans.

- The animal model should give the most precise and scientifically interpretable results. The model should present the least serious biological risk for the research team.

- The model should be reproducible and available.

- The animal model should have reasonable acquisition and care costs.

- The choice should also be directed toward the species requiring the fewest animals. Research should be conducted on the minimum number of animals to provide the maximum amount of information (see following section).

\section{LEGAL AND ETHICAL FRAMEWORK FOR ANIMAL RESEARCH: THREE BASIC Rs AND THE ADDITION OF A 4TH R}

The 3Rs rule was developed by Russel and Burch in 1959 (24) and forms the basis of the regulation and the ethical foundations of the use of animals for scientific purposes (25). This 3Rs rule is the replacement, the refinement, and the reduction in the number of animals.

Replacement refers to technologies or approaches offering similar results with the preferred use of non-animal methods (26). The replacement of in vivo models by in vitro (performed 
with microorganisms or cells outside their normal biological context), in silico (performed on computer or via computer simulation), or less sensitive animal species (called partial replacement with invertebrates which are not considered capable of experiencing suffering) is growing. However, computer models and in vitro studies cannot reproduce the entire complex and interactive system that is present in humans.

Reduction refers to methods (better statistical analysis and best quality study design) that minimize the number of animals used for studies (26). Reduction also includes methods of maximizing the information collected for each animal in a single experiment to reduce the use of additional animals.

Refinement refers to methods that minimize strain, stress, and pain over the lifetime of the animal by improving their living conditions. This concept considers the housing and breeding conditions of animals as well as the scientific procedures applied to them. It also relies on training animals to cooperate with procedures to minimize their distress and to use appropriate anesthesia or analgesia to minimize pain. Finally, it compasses the choice of the most appropriate method for euthanasia.

Although, the principles of the 3Rs are now internationally accepted as a criterion for animal use in research, it was not until several decades ago that regulations and guidelines governing the use of animals for scientific research emerged. Depending on the country and because of its potentially contentious nature, animal research is highly regulated by different jurisdictions (federal, state, municipal, and institutional). China $(20,496,000$ animal procedures), the United States of America (14,574,000 animal procedures), and Europe (9,800,000 animal procedures) are the three largest users of laboratory animals (21).

In China $(27,28)$, the legislation in force dates from 1983 with the first laboratory animal science regulations. The Ministry of Science and Technology (MOST) is responsible for its application with the help of the provincial administration (Provincial Department of Science and Technology). MOST oversees all relevant activities including breeding, import/export, licensing for production, and use of laboratory animals and personal training. In 2006, this Ministry published a first set of recommendations on the welfare of laboratory animals called "Guidelines on the Humane Treatment of Laboratory Animals." Institutional monitoring is also achieved through IACUC and its accrediting organization-the Association for Assessment and Accreditation of Laboratory Animal Care (AAALAC International), which evaluates animal research and testing.

In the USA (29), the main federal law concerning the protection of animals is the Animal Welfare Act and dates from 1966. This legal text concerns the treatment of animals, especially in research, and is limited to warm-blooded animals and does not concern mice and rats. Other laws including the Health Research Extension Act of 1985 covers additional species and includes more specifications for animal care and use. Associated with these fundamental texts are repositories of good practices, dedicated scientific organizations, and accreditation programs. These organizations aim to ensure the ethical monitoring of animal research mainly by mandating the research establishment of an Institutional Animal Care and use Committee (IACUC). An organization should also review all research protocols and ensure researchers strive to treat animals humanely using the $3 \mathrm{R}$ rule.
In Europe (30), the 2010/63/EU directive concerns all vertebrate and invertebrate animals and sets out the regulations relating to the protection of animals used for scientific purposes. The use of primates is limited to basic and medical research for serious diseases when it is not possible to use other animal species. The use of great apes is explicitly prohibited. Animals must come from approved farms or suppliers. Establishments performing the experiments as well as the breeding establishments must be approved and registered. This directive insists that any project requiring animal testing must be the subject of an ethical evaluation in order to obtain an authorization (for a maximum of 5 years) from the ministry of research and to submit to inspections carried out by the national authorities (31). More recently, a 4th R ("Responsibility") was added to the basic 3Rs to focus on the full integrity and honesty of scientists in the proper and reasonable use of laboratory animals $(19,32)$.

Lastly guidelines related to animal studies have been published. The Preferred Reporting Items for Animal Studies in Endodontology (PRIASE) 2021 guidelines were developed exclusively for the specialty of Endodontology by integrating and adapting the ARRIVE (Animals in Research: Reporting In Vivo Experiments) guidelines and the Clinical and Laboratory Images in Publications (CLIP) principles using a validated consensusbased methodology. Although, the existing ARRIVE guidelines can be applied to any field of biomedical sciences animal studies in Endodontology often require specialized endodontic information that are not included within any existing guidelines or other policy documents. The new PRIASE guidelines is a fivestep consensus process managed by a steering committee. The 11 domains and 43 sub-items are interested in title, keywords, abstract, introduction, materials and methods, results, discussion, conclusion, funding and support, conflict of interest, and quality of images. These new guidelines focus on improving the major principles necessary for the development of an animal study, on animal husbandry and welfare, to improve the quality, and reproducibility of studies to assess the consequences of treatments and their usefulness in guiding clinical studies in humans. These guidelines help authors to improve the quality of their animal studies, as well as the preparation of manuscripts, for peer review related to endodontology. The general adoption of these guidelines aims to guide authors to greater success, avoiding the pitfalls of working on poorly designed and poorly conducted animal studies that are not suitable for publication (33).

\section{ANIMAL MODELS OF PULPITIS INDUCTION}

\section{Pulpitis Induction Techniques}

Research in humans and animals has demonstrated the complex nature of the onset and resolution of inflammation. Three main animal models of pulp inflammation are found in the literature depending on the causal agent. The first induction technique consists of making class I (occlusal) or $\mathrm{V}$ (cervical third of the teeth) cavities with a $1 / 4$ round bur or an inverted-cone carbide bur under water spray until pulp exposure $(34,35)$. Some authors perform the trepanation of the pulp with the bur that was used 
to make the cavities while others use an endodontic hand file until the pulp becomes visible through the transparency of the dentin floor (36). The use of an endodontic hand file controls the pulp exposure diameter so that it is roughly the same on all samples, which helps to keep the development of inflammation as consistent as possible. Once the pulp is exposed, the tooth is left open to be colonized by bacteria present in the oral environment.

The second method also consists of creating cavities under the same conditions as previously described with or without pulp exposure. Once the cavity has been made, a exogenous supply of toxins such as lipopolysaccharide (LPS) (37), Streptococcus mutans (38), or human carious dentin (39) was placed either directly in contact with the pulp or at the bottom of the cavity so that the toxins diffuse through the dentinal tubules. LPS is a compound of the outer membranes of Gram-negative bacteria that binds TLR4 and TLR2 (for atypical LPS of $P$. gingivalis) of odontoblasts and induces the synthesis of proinflammatory cytokines and initiates the inflammatory response (40-42). Similar to application of isolated bacteria, the use of decayed human dentin, without pulp exposure, can induce an inflammatory response. The major problem with the use of carious dentin is the lack of control of the bacterial load, which can be standardized when using individual bacterial cultures (38). The cavity is then sealed with a light-cured resin or an amalgam to isolate it from the oral environment and from other potential bacterial contamination (37-39). This second method of induction require the installation of a sealed operating field (rubber dam) to avoid any oral bacterial contamination when making the cavities. These first two methods of induction also need the use of small surgical instruments as well as an operating microscope because of the often small size of animal teeth, to avoid the risk of perforation that can generate unwanted iatrogenic inflammation. Lastly, it should be borne in mind that the creation of the cavities requiring the use of burs generates a mechanical inflammation in addition to the inflammation induced secondarily by bacteria. Therefore, a control group assessing the effect of the drilling process alone is mandatory. Moreover, the cavities produced would need to be controlled (depth, drilling-time) and standardized with the use of modern non-invasive imaging technologies, such as micro-computed tomography $(\mu \mathrm{CT})$ since it allows data to be collected at several time-points, thereby reducing the numbers of animals needed to obtain data (33).

The third induction technique consists of using transgenic animal models. Genetically modified animals are animals whose chromosomes have been altered so that their genes contain foreign DNA. These genes are located in the nucleus of every cell in the body. Therefore, all cells contain the new DNA. Modifying DNA usually involves adding additional cell function, including the production of new proteins. Transgenesis is a technique that involves inactivation (Knock-out) or replacing (Knock-in) a portion of a gene in an entire organism to create new models for the study of human diseases. The most frequent models used are knock-out mice. By genetic modification, Knock-out (KO) model make it possible to study the role of a gene by observing the consequences of its inactivation by deleting and replacing it by an exogenous gene (reporter gene) or by a selection gene in the embryonic stem cells from which they are derived (43). This technique removes the gene from the beginning of the animal's life. Other techniques called conditional and inducible knock-out allows invalidation of a specific gene in a specific cell type and/or at a specific time in order to avoid possible side effects of conventional $\mathrm{KO}$ models especially embryonic death due to genetic mutations. Other genetic approach may also be considered. In a recent study, a transgenic mouse model was generated to conditionally overexpress TNF- $\alpha$ in the tooth pulp. Mice were bred with a dentin matrix protein 1 (DMP1)-Cre line for overexpression of TNF- $\alpha$ in both the tooth pulp and bone. These mice showed inflammation in the tooth pulp mimicking pulpitis (44).

\section{Methods for Assessment of Pulp Inflammation}

Different analysis techniques can assess the level of pulpal induced-inflammation. The combination of several techniques is useful depending on the objective of the study. Histopathological analysis with hematoxylin-eosin ( $\mathrm{H} \& \mathrm{E})$ staining is the most frequent evaluation method and is found in more than $90 \%$ of studies. This biochromatic staining is composed of a nuclear (hematoxylin) and a cytoplasmic (eosin) dye that offers microscopic examination of tissues that have been decalcified, fixed, processed, embedded, and sectioned (45). Hematoxylin is a cationic dye that binds to acidic structures and stains them in blue (DNA in the nucleus, RNA in cytoplasm, and ribosomes). Eosin is an anionic dye that binds basic structures and colors them in red or pink (proteins, extracellular fibers). Some studies also use Masson's trichrome staining which is a trichromatic staining associating a nuclear staining (hematoxylin), a cytoplasmic staining by a mixture of acid dyes and an elective staining of collagen. To evaluate pulpitis inflammation and inflammatory cells, sections with a complete pulp chamber, root canal, and periapical area are performed. After staining, quantitative and qualitative histopathologic analyses are achieved using different parameters (location of inflammatory cells, intensity of inflammatory infiltrate, inflammatory edema, vascular leakage, extension of pulp necrosis) (46). The evaluation rating is then evaluated by a score from the best outcome to the most severe (34, 38). The inflammatory pattern of pulpitis can also be confirmed by analysis of inflammatory markers. Some authors have used total cellular RNA from stimulated pulp tissues of mice's molars to perform real-time polymerase chain reaction (RT-PCR) by targeting pro-inflammatory cytokines like IL- $1 \beta$, IL- 6 , and TNF$\alpha$ (36). Others have used enzyme-linked immunosorbent assay (ELISA) to directly quantify these pro-inflammatory cytokines from samples of pulp tissue homogenates (47). Finally, cell surface marker expression may be assessed using flow cytometry. A combination of the different methods can provide a wider range of data rather than the use of only one technique provided that the amount of pulp tissue is sufficient (48) (Figure 1).

\section{Animal Model of Pulpitis}

Several animals have been used to study and develop models of pulpitis induction during the last 40 years (mice, rats, dogs, 
A

Animal selection strategies

\begin{tabular}{|l|c|c|c|c|c|c|c|}
\hline & Mouse & Rat & Ferret & Cat & Dog & Minipig & Monkey \\
\hline \begin{tabular}{l}
\hline \\
Ease of establishing \\
pulpris
\end{tabular} & $\checkmark$ & $\checkmark$ & $\checkmark$ & $\checkmark$ & $\checkmark$ & $\checkmark$ & $\checkmark$ \\
\hline Relative cost & $\checkmark$ & $\checkmark$ & $\checkmark$ & $\checkmark$ & $\checkmark$ & $\checkmark$ & $\times$ \\
\hline $\begin{array}{l}\text { Proximity to human } \\
\text { dental anatomy }\end{array}$ & $\checkmark$ & $\checkmark$ & $\checkmark$ & $\checkmark$ & $\checkmark$ & $\checkmark$ & $\checkmark$ \\
\hline $\begin{array}{l}\text { Social and ethical } \\
\text { issues }\end{array}$ & $\checkmark$ & $\checkmark$ & $\checkmark$ & $\checkmark$ & $\checkmark$ & $\checkmark$ & $\times$ \\
\hline $\begin{array}{l}\text { Knowledge on the } \\
\text { model }\end{array}$ & $\checkmark$ & $\checkmark$ & $\checkmark$ & $\checkmark$ & $\checkmark$ & $\checkmark$ & $\checkmark$ \\
\hline Phylogenetic distance & $\checkmark$ & $\checkmark$ & $\checkmark$ & $\checkmark$ & $\checkmark$ & $\checkmark$ & $\checkmark$ \\
\hline
\end{tabular}

B Pulpitis induction strategies

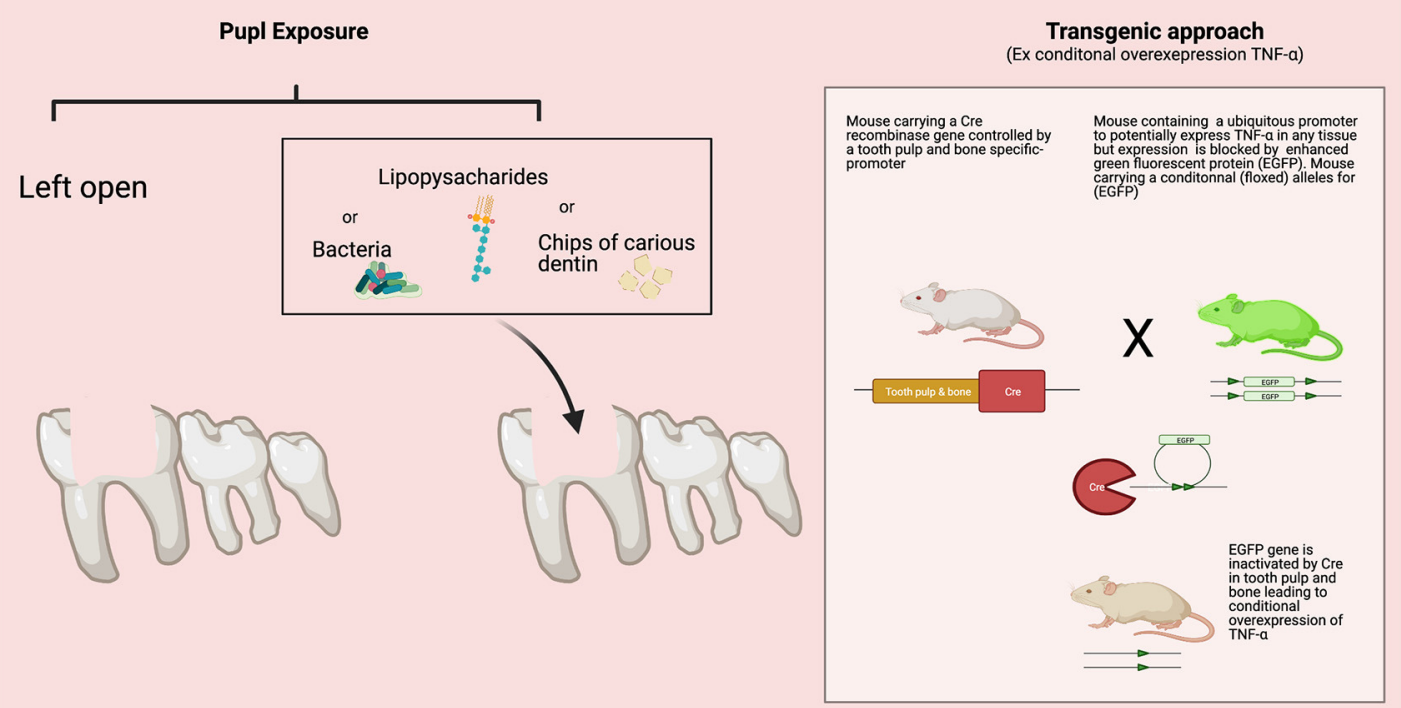

C

\section{Assesment of pulp inflammation}

2D and 3D Radiological analyses $(\mu \mathrm{CT}$,

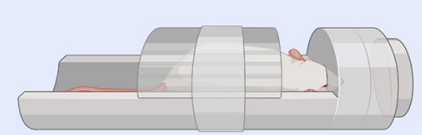

Histology

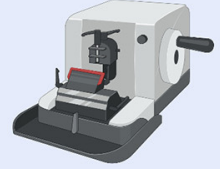

Flow cytometry

analyzes
mRNA gene
expression \& protein analyzes

FIGURE 1 | Animal models to study pulp inflammation. (A) Criteria to define the optimal choice of the animal model to study pulp inflammation. (B) Different methods can be used to induce pulp inflammation. (C) Complementary methods to assess pulp inflammation in rat incisors. Figure was created with BioRender.com. 
monkeys, etc.). The Table 1 summarizes all the data on the different animal models used to create inflammatory conditions of pulpitis.

\section{Non-human Primates}

The first studies of induced pulpitis were performed over half a century ago on monkeys (35). The initial objective of these studies was to develop a model that would permit study of the healing processes of pulpal inflammation and the effect of operative procedures and restorative materials under situations that simulate clinical conditions. Class V cavities were performed without pulp exposure and were then filled either with soft human carious dentine covered with amalgam or with guttapercha or left open without further treatment for 8 days. In a study conducted by Furseth et al., histological analysis (H\&E) and scanning electron microscopy staining were performed to evaluate the reaction of the underlying pulp tissue (55). A severe inflammatory reaction was found in the teeth treated with infected dentin (probably due to toxins and degradable products) and a slight to moderate inflammation in the group treated with gutta-percha. They concluded that different forms of pulpitis can be reproducibly induced in monkey teeth (55).

These studies had the advantage of having been carried out in monkeys, which are the closest animal to humans from an anatomical, physiological, and biological point of view. Nonhuman primates are accepted models to analyze tissue pathology and healing because they can be extrapolated to humans (56). However, these studies do not specify which tooth has been treated or the age of the monkeys. They are only satisfied with histological analysis to quantify pulpal inflammation. In addition, the analysis times after induction of inflammation are, regardless of the study, limited to one or two times and do not exceed 14 days. These old studies show biases, associated with a weakness of the materials and methods which is a major limitation. These studies would deserve to be completed and standardized, but the use of non-human primates is today much more complex, particularly in terms of legislation.

More recently, due to the difficulty in obtaining human carious dentin, Cleaton-Jones et al. (38) studied if pulpitis induced by a colony of Streptococcus mutans may be similar to that obtained with decayed dentin in monkeys. The first molars of each jaws of two juvenile baboons were isolated with a rubber dam and occlusal cavities were created with pulp exposure of $1 \mathrm{~mm}$ in diameter with a round steel bur. Cavities were then filled either with soft fresh human carious dentin or with single 24-h colonies of Streptococcus mutans in agar. After 14 days, histological analysis was performed with $\mathrm{H} \& \mathrm{E}$ staining and Brown-Brenn staining to visualize and differentiate Gram-positive and Gram-negative bacteria. Both induction methods induced pulp inflammation (characterized by edema and pulp reduced to strands of tissue), but the use of a Streptococcus mutans colony produced a less severe pulpitis and more reproducible results. This can be explained by the fact that the bacterial load is greater in decayed dentin and that the $S$. mutans bacterial colony can be more easily standardized.

The use of non-human primates as an animal model in research was progressively limited and framed and largely related to ethical issues. They are only used in scientific experiments when there is no other method or species that can serve as an alternative. Primates are primarily used in vaccine development and to test drugs that might have effects on female genitals, eyes, blood clotting, or the brain because they are the only mammals to exhibit specific physiological traits similar to humans (23). They are the closest species to humans in terms of physiology and immune response. Primates are often the most suitable animals for infectious disease research due to their close phylogenetic relationship to humans and their similarities in terms of genetics, behavioral, and biochemical activities (2005). These models still have certain limitations such as zoonotic risks (linked to their phylogenic proximity), supply difficulties, and a high cost of purchase and maintenance.

The monkey may be considered as a model of choice for inducing pulpitis. However, the current scientific consensus is that non-human primates use is justified only in a small number of specific cases excluding pulpitis simulation (Figure 1).

\section{Murine Models}

Murine models have many advantages: they are small animals, readily available, inexpensive compared to other animals, easy to handle, and facilitate studies on a higher number of animals (allowing to obtain more reproducible results). In the literature, pulpal inflammation in murine models could be reproducibly induced by pulpal stimulation with exogenous toxins or by bacterial infection from the oral environment.

He et al. used C57BL/6 mice to induce pulpal inflammation by exposing the pulp for $1,6,12,24,48$, and $72 \mathrm{~h}$ to the oral environment (36). Here, occlusal class I cavities were performed on upper first molars with a $1 / 4$ dental round bur under a surgical microscope. The pulp was then exposed using an endodontic hand file (15/100,2\%). The same protocol, with C57BL/ 6 mice, was used by Shi's team with the only exception that the pulp exposure was performed either with a $1 / 4$ round bur or with a polishing bur to see the effect of different burs on the induction of inflammation (34). Micro-CT analysis was performed to visualize the pulp, the peri-apical area, the size of the pulpal exposure, and possible fracture or perforation. Pulpal inflammation was then assessed by histopathological analysis (H\&E) $(34,36)$ and by RT-PCR for IL-1 $\beta$, IL-6, and TNF- $\alpha$ proinflammatory cytokines mRNA expression in pulpal stimulated tissue (36). He et al. observed significant pulpal tissue changes in the face of inflammation with significantly higher levels of pro-inflammatory cytokine gene expression at 6 and $12 \mathrm{~h}$.

Pulpitis induced by pulpal exposure and oral contamination seems to be a good induction model to simulate the clinical development of pulpitis. Although the operating protocol does not involve many steps, it requires surgical skills and materials such as operating microscope because of a narrow oral cavity and small teeth. Moreover, the size of the access hole and materials used to create the pulp exposure appears to have an impact on the induction kinetics of inflammation $(34,35)$.

The same pulpitis induction protocol leaving the teeth open was also tested by $\mathrm{Li}$ et al. on Sprague-Dawley rats (50). Teeth were left open for 1,3 , and 5 days, and DAB staining 
TABLE 1 | Summary of pulpitis animal models.

\begin{tabular}{|c|c|c|c|c|c|}
\hline & Animal model & $\begin{array}{l}\text { Pulpitis induction } \\
\text { technique }\end{array}$ & $\begin{array}{l}\text { Analysis techniques of } \\
\text { inflammation }\end{array}$ & Benefits & Drawbacks \\
\hline He et al. (36) & Mouse: upper first molars & Teeth left open & $\begin{array}{l}\text { Micro-CT, histopathological } \\
\text { analysis (H\&E staining), RT-PCR }\end{array}$ & $\begin{array}{l}\text { - Studies with many } \\
\text { animals } \\
\text { - Cost } \\
\text { - Reproducibility } \\
\text { - Transgenic model }\end{array}$ & $\begin{array}{l}\text { - } \text { Phylogenetic } \\
\text { distance from } \\
\text { humans } \\
\text { - Small teeth, difficulty } \\
\text { to access and } \\
\text { operate } \\
\text { - } \text { Microscope } \\
\text { and micro- } \\
\text { instruments }\end{array}$ \\
\hline Shi et al. (34) & Mouse: upper first molars & Teeth left open & $\begin{array}{l}\text { Histopathological analysis (H\&E } \\
\text { staining) }\end{array}$ & & \\
\hline Chung et al. (37) & Mouse: upper first molars & LPS application & $\begin{array}{l}\text { Immunohistochemical analysis } \\
\text { (CD-45), Western Blot analysis, } \\
\text { RT-PCR }\end{array}$ & & \\
\hline Hall et al. (44) & Transgenic mouse: & Over expression of TNF- $\alpha$ & $\begin{array}{l}\text { Immunohistochemical analysis, } \\
\text { Western Blot, ELISA, PCR }\end{array}$ & & \\
\hline Okiji et al. (49) & Rat: upper incisor & LPS application & $\begin{array}{l}\text { High performance liquid } \\
\text { chromatography, } \\
\text { radiochromatoscanning }\end{array}$ & & \\
\hline Li et al. (50) & $\begin{array}{l}\text { Rat: upper first and second } \\
\text { molars }\end{array}$ & Teeth left open & $\begin{array}{l}\text { Histopathological analysis (H\&E } \\
\text { and DAB staining), ELISA, } \\
\text { Western Blot, qRT-PCR }\end{array}$ & & \\
\hline Renard et al. (48) & Rat: upper incisor & LPS application & Histological analysis, RT-PCR & & \\
\hline $\begin{array}{l}\text { Chattipakorn et al. } \\
\text { (51) }\end{array}$ & Ferret: maxillary canines & LPS application & $\begin{array}{l}\text { Immunohistochemical analysis, } \\
\text { Histopathological analysis, }\end{array}$ & $\begin{array}{l}\text { - Intermediate size } \\
\text { between rodents and } \\
\text { canine model } \\
\text { - Cost }\end{array}$ & $\begin{array}{l}\text { - Few studies } \\
\text { concerning } \\
\text { pulpitis induction }\end{array}$ \\
\hline $\begin{array}{l}\text { Songsiripradubboon } \\
\text { et al. (52) }\end{array}$ & $\begin{array}{l}\text { Beagle dog: upper and } \\
\text { lower second premolars }\end{array}$ & LPS application & Histopathological analysis & $\begin{array}{l}\text { - Good behavioral } \\
\text { characteristics } \\
\text { - Size }\end{array}$ & - Cost \\
\hline Eba et al. (47) & $\begin{array}{l}\text { Beagle dog: upper and } \\
\text { lower premolars }\end{array}$ & Teeth left open & $\begin{array}{l}\text { Histopathological analysis (H\&E } \\
\text { and Masson trichrome staining), } \\
\text { ELISA }\end{array}$ & & \\
\hline Shahravan et al. (39) & $\begin{array}{l}\text { Beagle dog: upper and } \\
\text { lower teeth }\end{array}$ & $\begin{array}{l}\text { Soft human dentin } \\
\text { application }\end{array}$ & $\begin{array}{l}\text { Histopathological analysis (H\&E } \\
\text { staining) }\end{array}$ & & \\
\hline Moradi et al. (53) & Cat: canines & Teeth left open & $\begin{array}{l}\text { Histopathological analysis (H\&E } \\
\text { staining) }\end{array}$ & - Simple maintenance & $\begin{array}{l}\text { - Mainly used in } \\
\text { neurology } \\
\text { and ophthalmology }\end{array}$ \\
\hline Meto et al. (54) & $\begin{array}{l}\text { Minipig: upper and lower } \\
\text { incisors }\end{array}$ & Polybacterial application & $\begin{array}{l}\text { Histopathological analysis (H\&E } \\
\text { staining) }\end{array}$ & - Close to human & - Cost \\
\hline Mjör et al. (35) & $\begin{array}{l}\text { Monkey: teeth not } \\
\text { mentioned }\end{array}$ & $\begin{array}{l}\text { Soft human dentin } \\
\text { application, gutta percha } \\
\text { obturation and teeth left } \\
\text { open }\end{array}$ & $\begin{array}{l}\text { Histopathological analysis (H\&E } \\
\text { staining) }\end{array}$ & $\begin{array}{l}\text { - Dental anatomy and } \\
\text { physiology close } \\
\text { to humans }\end{array}$ & $\begin{array}{l}\text { - Social and ethical } \\
\text { issues } \\
\text { - Expensive } \\
\text { - Model size and } \\
\text { breeding conditions }\end{array}$ \\
\hline Furseth (55) & $\begin{array}{l}\text { Monkey: teeth not } \\
\text { mentioned }\end{array}$ & $\begin{array}{l}\text { Soft human dentin } \\
\text { application }\end{array}$ & Scanning electron microscopy & & \\
\hline Fuks et al. (56) & $\begin{array}{l}\text { Monkey: teeth not } \\
\text { mentioned }\end{array}$ & $\begin{array}{l}\text { Soft human dentin } \\
\text { application }\end{array}$ & $\begin{array}{l}\text { Histopathological analysis (H\&E } \\
\text { staining) }\end{array}$ & & \\
\hline $\begin{array}{l}\text { Cleaton-Jones et al. } \\
\text { (38) }\end{array}$ & Monkey: primary molars & $\begin{array}{l}\text { Soft human dentin or } \\
\text { Streptococcus mutans } \\
\text { application }\end{array}$ & $\begin{array}{l}\text { Histopathological analysis (H\&E } \\
\text { and Brown-Brenn staining) }\end{array}$ & & \\
\hline
\end{tabular}

immunohistochemical analysis was done for TLR4 and NF$\kappa \mathrm{B}$; an ELISA analysis was used to evaluate cytokines levels (IL-1 $\beta$, IL-8, and TNF- $\alpha$ ). At 1 and 3 days, the exposed pulp showed a significant increase in the number of inflammatory cells, compared to teeth without any treatment. ELISA tests also confirmed an increase in pro-inflammatory cytokines with a peak 1 day after induction. This increase was correlated with the up-regulation of TLR4 and NF-KB expression at 1 day. 
Other pulpitis-induction protocols have also been tested in mice such as the use of LPS of Escherichia coli (E. coli). Chung used $\mathrm{C} 57 \mathrm{BL} / 6$ mice in which cavities on the maxillary first molars without pulpal exposure were made (37). The LPS is then applied using a fine paper point in the cavities. Cavities are then dried, and this wet-and-dry procedure was repeated 5 or 6 times. Cavities were then filled with light cured resin to avoid oral bacteria contamination. Immunohistochemistry was done after $4 \mathrm{~h}$ to stain CD45 and to label leukocytes in dental pulp. This study showed that the recruitment of inflammatory cells is greater in the LPS group, compared to the control group treated with saline solution, suggesting that dentinal LPS application can evoke the diffusion of bacterial toxins through the dentinal tubules (as during carious disease) leading to a localized inflammatory reaction. The main advantage of this technique is that it remains less-invasive (without direct pulp injury) in causing a mechanical pulpal inflammation.

Another study used also LPS to induce pulpal inflammation in rats upper incisors (48). In their study, LPS of E. coli was directly applied in contact with the pulp previously sectioned horizontally and then sealed with a temporary filling material. Infiltrated inflammatory cells were observed $9 \mathrm{~h}$ after pulp injury by Masson trichrome staining and immunohistochemistry for macrophage detection. They found an increase in the mRNA expression of proinflammatory cytokines (IL-6, IL-1 $\beta$, TNF- $\alpha$, IL-10) with a peak observed at $3 \mathrm{~h}$ in the teeth stimulated with LPS. In teeth treated with Phosphate Buffer Saline (used as a control) the area of infiltration by inflammatory cells was smaller than in the LPStreated teeth. This rapid inflammatory response can be explained by the double inflammatory stimulation (pulp exposure and LPS stimulation) and by the fact that this study was performed on rodent incisor models, which are continuously-erupting open apex teeth with high vascularity and healing capability. Although different from molars in terms of function and anatomy, the incisors allow sufficient pulpal material to be collected for flow cytometry analysis.

It is generally accepted that the development of rats and mice immune system is comparable, but much more information is available for the mouse (57). Moreover, there are differences between results obtained in mice and rats. For instance, several studies have shown that immune parameters in mice are more sensitive to the effects of stress (as measured by corticosterone) compared with rats $(58,59)$. Even if rodents are the mainstay of in vivo immunological experimentation, it is important to point out that the immune systems of mice/rats and humans are quite similar but present some differences (60), especially in the development, activation, and response to aggression. For example, the blood cell proportion of neutrophil and lymphocytes are different (50$70 \%$ of neutrophils and $30-50 \%$ of lymphocytes in human blood vs. $75-90 \%$ of lymphocytes and $10-25 \%$ of neutrophils in mouse blood). Toll-like receptors, defensins, cytokines, and cytokine receptors (60) vary between humans and rodents. It is therefore necessary to consider the possibility that a given murine model response may not occur in exactly the same way in humans (Figure 1).

\section{Larger Animal Models}

Pulpitis-induction models were also performed in larger animals with similar results. The main advantage of using larger animals is the similarity of the organ size facilitating procedures such as dental dam placement and allowing to mimic operating techniques clinically used in humans.

Ferrets have also been used in endodontic research for many years. Their canines have a clinical crown big enough to perform clinical pulpal procedures in a realistic manner, close to human (61). Pulpitis has been induced in ferrets by application of LPS of E. coli on the floor of the preparation of canines, which were then filled with a light-cured composite resin. The control group consisted of the application of saline solution in the cavity. Histological analysis showed the presence of neutrophils and macrophages at 3 days indicating a stage of acute pulpal inflammation (51).

Dogs have also been used as an animal model of pulpitis induction $(39,47,52)$. Incisors, canines, and premolars of dogs are anatomically close to those of humans. Incisors, canines, first premolars, and the third mandibular molars are all single rooted. The only three rooted teeth in dogs are the maxillary fourth premolar and first and second molars. All other teeth have two roots (62). Similarly, dogs shares many biochemical and physiologic characteristics with humans (63) particularly concerning the immune system (64) with several validated immune markers in canine (65). Canine models mainly use beagle dogs. Three induction protocols have been tested and used in dogs: with soft carious dentin (39), with teeth left open in oral environment (47), and with E. coli LPS application on the cavity floor (52). In the group of teeth treated with soft human carious dentin, moderate to severe inflammation was seen 7 days after induction characterized by hyperemia and fibrosis with H\&E staining. Teeth exposed to bacteria of the oral environment showed, after H\&E and Masson trichrome staining, a mild pulpitis after $24 \mathrm{~h}$ (hyperemia, blood vessel dilatation, and neutrophil infiltration in the pulp tissue underneath the amputated site) and severe pulpitis after $72 \mathrm{~h}$ of exposition (inflammatory cells dispersed throughout the upper half of the pulp). Finally, pulpitis induction with LPS in deep cavities without pulp exposure also induced an inflammatory response after 14 days with accumulation of chronic inflammatory cells beneath the dentin and normal pulp tissue morphology in the pulp distant from the dentin (52). It is difficult to consider a comparison between the protocols because, on the one hand, the inflammation assessment time are not carried out over the same period ( 24 and $72 \mathrm{~h}$ vs. 14 days) and the LPS application techniques are different, with or without pulp exposure.

Swine are another animal model increasingly used in dental research (66). They look like humans in many ways and especially in terms of anatomy and tooth morphology. For example, the second lateral incisors are similar to human maxillary lateral incisors or mandibular incisors. Second, the third and fourth premolars are closest to humans premolars or molars and are suitable teeth for experiments (61). This animal model also has the advantages of being a suitable size for dental manipulations. Comparative genetic maps (arrangement of genes or markers 
on chromosomes) also indicate that there is more structural similarities between mini-swine and human than mouse and human (67). However, their cost makes them a major drawback ( $\sim 100$ times more). Few studies using swine teeth to induce models of pulpitis are found in the literature. A study by Meto (54) used maxillary and mandibular swine incisors on which they made class $\mathrm{V}$ cavities that were then contaminated with microbial flora (Staphylococcus aureus, Streptococcus viridans, and Enterococcus faecalis) to cause pulpitis. After $2 \mathrm{~h}$, the histological analysis showed hyperemia, dilatation of capillaries, and inflammatory cells (polymorphonuclear cells) confirming the inflammation. Purulent inflammation was observed in more than half of the cases over longer times ( 5 and 7 days).

LPS is the most common stimulus used to study in vivo pulp inflammation. Another component of the Grampositive bacterial cell (Lipoteichoic acid (LTA) may induce pulp inflammation is relevant to study since it will bind to different Toll Like Receptors. A very few study compared LPS and LTA and showed that the inflammation generated by LPS was greater than with LTA $(68,69)$. Oliveira et al. demonstrated in dog's teeth that, $150 \mu \mathrm{g} / \mathrm{ml}$, LPS and LTA affect pulp, leading to destruction of the pulp tissue and that less damage was caused by LTA than by LPS (69).

\section{Transgenic Models}

An alternative pulpitis-induction model is based on the use of transgenic animals such as the inducible TNF- $\alpha$ glo transgenic mouse model presented in Hall's study (44). This model has a ubiquitous promoter that could allow TNF- $\alpha$ expression in tooth and alveolar bone. The Cre-Lox conditional system has been used in this model. TNF- $\alpha$ expression is stopped by an enhanced green fluorescent protein (EGFP) sequence that must be excised by the "Cre recombinase" to be expressed. In this model, expression of the Cre recombinase has been restricted to the DMP-1 expressing cells. Thus, these mice allow conditionally overexpression of TNF- $\alpha$ in tooth pulp to promote pulpitis and in bone tissues. TNF- $\alpha$ is a pro-inflammatory cytokine that stimulates vasodilatation, induces chemotaxis, recruit leukocytes, activate neutrophils, and induces the stimulation of other proinflammatory cytokines (70). This study used Western Blot and immunohistochemistry to show a link between increased levels of TNF- $\alpha$ and acute inflammation in patients with dental caries and pulpitis. In the genetic mouse model, the overexpression of TNF$\alpha$ alone leads to pulp inflammation mimicking acute pulpitis (inflammatory infiltrates and dilatation of blood vessels). These transgenic models have the advantage of being less expensive than large animal models and can facilitate surgical techniques of inflammation induction (no cavity preparation). However, offtarget effects are important to consider especially in inducible transgenic model. In the study of hall et al. the TNF- $\alpha^{\text {glo }}$ mice were bred with the dentin matrix protein 1 (DMP1)-Cre transgenic line and TNF- $\alpha$ was genetically upregulated solely in the odontoblasts, osteoblasts and osteocytes using the DMP1Cre mouse line. DMP1/TNF- $\alpha^{\text {glo }}$ pups were born at the expected genotypic ratio and were phenotypically normal at birth.

\section{CONCLUSION}

The study of the dental pulp inflammation in its physiopathological dimension still need animal models. The existing experimental alternatives (3D tissue printing, reconstructing an organ on a chip, computer modeling in silico) can supplement animal experimentation but cannot replace it in any way. The substitution remains limited due to the complexity of living things.

However, it is possible in the future, to consider artificially generated caries-inducing models that would represent a more elegant and closer to reality models than mechanical injury and LPS stimulation, and would also avoid off-target effects of the transgenic models. The limits of this kind of model, without the application of an inflammatory mechanical stimuli, could be the time to generate this inflammation, the differences in bacterial flora between human and animals.

Additionally, new diagnostic devices such as Magnetic resonance imaging (MRI) can be successfully used to visualize pulp morphology as well as pulp vitality and regeneration (71). In contrast with computed tomographic imaging, MRI can give insight into chemical, vascular, and edematous properties of a lesion; soft tissue processes like inflammations could be accurately visualized (72). As the use of MRI in the endodontic field is likely to increase in the future, improvements such as ultra-high field MRI may help to monitor pulp inflammation in animal models.

Medical and dental research therefore still needs animals to obtain reliable results that can be transferred to benefit humans. This is true for pulpitis induction models. Thus, it is necessary to choose the model most suited to the goal of the study, to the analysis techniques to be implemented, and to the financial means available.

\section{AUTHOR CONTRIBUTIONS}

We declare that all authors have contributed significantly and are in agreement with the manuscript.

\section{REFERENCES}

1. Di Nardo Di Maio F, Lohinai Z, D’Arcangelo C, De Fazio PE, Speranza L, De Lutiis MA, et al. Nitric oxide synthase in healthy and inflamed human dental pulp. J Dent Res. (2004) 83:312-6. doi: 10.1177/154405910408300408

2. Dommisch H, Winter J, Willebrand C, Eberhard J, Jepsen S. Immune regulatory functions of human beta-defensin-2 in odontoblast-like cells. Int Endod J. (2007) 40:300-7. doi: 10.1111/j.0143-2885.2007.01228.x

3. Cooper PR, Takahashi Y, Graham LW, Simon S, Imazato S, Smith AJ. Inflammation-regeneration interplay in the dentinepulp complex. J Dent. (2010) 38:687-97. doi: 10.1016/j.jdent.2010. 05.016

4. Farges J-C, Bellanger A, Ducret M, Aubert-Foucher E, Richard B, Alliot-Licht B, et al. Human odontoblast-like cells produce nitric oxide with antibacterial activity upon TLR2 activation. Front Physiol. (2015) 6:185. doi: $10.3389 /$ fphys.2015.00185 
5. Farges J, Alliot-licht B, Baudouin C, Msika P, Bleicher F, Carrouel F. Odontoblast control of dental pulp inflammation triggered by cariogenic bacteria. Front Physiol. (2013) 4:326. doi: 10.3389/fphys.2013.00326

6. Serhan CN, Chiang N, Dalli J. The resolution code of acute inflammation: novel pro-resolving lipid mediators in resolution. Semin Immunol. (2015) 27:200-15. doi: 10.1016/j.smim.2015.03.004

7. Ortega-Gomez A, Perretti M, Soehnlein O. Resolution of inflammation: an integrated view. EMBO Mol Med. (2013) 5:661-74. doi: 10.1002/emmm.201202382

8. Simon S, Cooper P, Lumley P, Smith AJ, Berdal A, Tomson P, et al. Understanding pulp biology for routine clinical practice. Endod Pract Today. (2009) 3:171-84.

9. Loison-Robert LS, Tassin M, Bonte E, Berbar T, Isaac J, Berdal A, et al. In vitro effects of two silicate-based materials, Biodentine and BioRoot RCS, on dental pulp stem cells in models of reactionary and reparative dentinogenesis. PLoS ONE. (2018) 13:e0190014. doi: 10.1371/journal.pone.0190014

10. Boyle M, Chun C, Strojny C, Narayanan R, Bartholomew A, Sundivakkam $\mathrm{P}$, et al. Chronic inflammation and angiogenic signaling axis impairs differentiation of dental-pulp stem cells. PLoS ONE. (2014) 9:e0113419. doi: 10.1371/journal.pone.0113419

11. Feng J, Mantesso A, De Bari C, Nishiyama A, Sharpe PT. Dual origin of mesenchymal stem cells contributing to organ growth and repair. Proc Natl Acad Sci USA. (2011) 108:6503-8. doi: 10.1073/pnas.1015449108

12. Vidovic-Zdrilic I, Vining KH, Vijaykumar A, Kalajzic I, Mooney DJ, Mina M. FGF2 enhances odontoblast differentiation by $\alpha \mathrm{SMA}(+)$ progenitors In Vivo. J Dent Res. (2018) 97:1170-7. doi: 10.1177/0022034518769827

13. Goldberg M. Pulp healing and regeneration: more questions than answers. Adv Dent Res. (2011) 23:270-4. doi: 10.1177/0022034511405385

14. Yin J, Xu J, Cheng R, Shao M, Qin Y, Yang H, et al. Role of connexin 43 in odontoblastic differentiation and structural maintenance in pulp damage repair. Int J Oral Sci. (2021) 13:1. doi: 10.1038/s41368-020-00105-1

15. Mangione F, EzEldeen M, Bardet C, Lesieur J, Bonneau M, Decup F, et al. Implanted dental pulp cells fail to induce regeneration in partial pulpotomies. J Dent Res. (2017) 96:1406-13. doi: 10.1177/0022034517725523

16. Goldberg M, Kulkarmi A, Young M, Boskey A. Dentin: structure, composition and mineralization: the role of dentin ECM in dentin formation and mineralization. Front Biosci. (2012) 3:e281. doi: 10.2741/e281

17. Wynn TA, Ramalingam TR. Mechanisms of fibrosis: therapeutic translation for fibrotic disease. Nat Med. (2012) 18:1028-40. doi: 10.1038/nm.2807

18. Goldberg $\mathrm{M}$, Njeh A, Uzunoglu E. Is pulp Inflammation a prerequisite for pulp healing and regeneration? Mediators Inflamm. (2015) 2015:347649. doi: 10.1155/2015/347649

19. Mushtaq S, Daş YK, Aksoy A. Alternative methods to animal experiments. Turkiye Klin J Med Sci. (2018) 38:161-70. doi: 10.5336/jlabanim.201859993

20. Doke SK, Dhawale SC. Alternatives to animal testing: a review. Saudi Pharm J SPJ Off Publ Saudi Pharm Soc. (2015) 23:223-9. doi: 10.1016/j.jsps.2013. 11.002

21. Taylor K, Alvarez LR. An estimate of the number of animals used for scientific purposes worldwide in 2015. Altern Lab Anim. (2019) 47:196213. doi: $10.1177 / 0261192919899853$

22. FDA. Product Development Under the Animal Rule - Guidance for Industry. Silver Spring, MD: Food Drug Adm (2015). p. 1-54.

23. Andersen ML, Winter LMF. Animal models in biological and biomedical research - experimental and ethical concerns. An Acad Bras Cienc. (2019) 91:e20170238. doi: 10.1590/0001-3765201720170238

24. Russell WMS, Burch RL. The Principles of Humane Experimental Technique [Internet]. London: Methuen (1959).

25. Hampshire VA, Gilbert SH. Refinement, reduction, and replacement (3r) strategies in preclinical testing of medical devices. Toxicol Pathol. (2019) 47:329-38. doi: 10.1177/0192623318797289

26. Schechtman LM. Implementation of the 3Rs (refinement, reduction, and replacement): validation and regulatory acceptance considerations for alternative toxicological test methods. ILAR J. (2002) 43:85-94. doi: 10.1093/ilar.43.Suppl_1.S85

27. Ogden BE, Pang W, Agui T, Lee BH. Laboratory animal laws, regulations, guidelines and standards in China Mainland, Japan, and Korea. ILAR J. (2016) 57:301-11. doi: 10.1093/ilar/ilw018
28. Bayne K, Wang J. Oversight of animal research in China. Lab Anim Regul Recomm Glob Collab Res. (2014):24366. doi: 10.1016/B978-0-12-397856-1.00009-X

29. Cheluvappa R, Scowen P, Eri R. Ethics of animal research in human disease remediation, its institutional teaching; and alternatives to animal experimentation. Pharmacol Res Perspect. (2017) 5:1-14. doi: $10.1002 /$ prp2.332

30. Combrisson H. Expérimentation animale, peut-on s'en passer? Transfus Clin Biol. (2017) 24:93-5. doi: 10.1016/j.tracli.2017.06.005

31. Bodies AW. National Competent Authorities for the implementation of Directive 2010 / 63 / EU on the protection of animals used for scientific purposes. A working document on Animal Welfare Bodies and National Committees to fulfil the requirements under the Directive. Brussels: European Commission (2014). p. 9-10.

32. Pereira S, Tettamanti M. Ahimsa and alternatives - the concept of the 4 th $\mathrm{R}$. The CPCSEA in India. ALTEX. (2005) 22:3-6.

33. Nagendrababu V, Kishen A, Murray PE, Nekoofar MH, de Figueiredo JAP, Priya E, et al. PRIASE 2021 guidelines for reporting animal studies in endodontology: explanation and elaboration. Int Endod J. (2021) 2021:168999. doi: 10.1111/iej.13481

34. Shi X, Li Z, He Y, Jiang Q, Yang X. Effect of different dental burs for experimental induction of pulpitis in mice. Arch Oral Biol. (2017) 83:252-7. doi: 10.1016/j.archoralbio.2017.08.002

35. Mjör IA, Tronstad L. Experimentally induced pulpitis. Oral Surg Oral Med Oral Pathol. (1972) 34:102-8. doi: 10.1016/0030-4220(72)90278-2

36. He Y, Gan Y, Lu J, Feng Q, Wang H, Guan H, et al. Pulpal Tissue inflammatory reactions after experimental pulpal exposure in mice. J Endod. (2017) 43:905. doi: 10.1016/j.joen.2016.09.003

37. Chung MK, Lee J, Duraes G, Ro JY. Lipopolysaccharide-induced pulpitis up-regulates TRPV1 in trigeminal ganglia. J Dent Res. (2011) 90:11037. doi: $10.1177 / 0022034511413284$

38. Cleaton-Jones P, Duggal M, Parak R, Williams S, Setzer S. Pulpitis induction in baboon primary teeth using carious dentine or Streptococcus mutans. SADJ. (2004) 59:119-22.

39. Shahravan A, Ghoddusi J, Eslami B, Rategar AF. A histopathological study of the pulp of dogs' teeth after induction of experimental pulp inflammation for different periods of time. J Microsc. (2010) 237:11921. doi: 10.1111/j.1365-2818.2009.03312.x

40. Staquet MM-J, Durand SH, Colomb E, Roméas A, Vincent C, Bleicher F, et al. Different roles of odontoblasts and fibroblasts in immunity. J Dent Res. (2008) 87:256-61. doi: 10.1177/154405910808700304

41. Veerayutthwilai O, Byers MR, Pham T-TT, Darveau RP, Dale B. Differential regulation of immune responses by odontoblasts. Oral Microbiol Immunol. (2007) 22:5-13. doi: 10.1111/j.1399-302X.2007.00310.x

42. Jang JH, Shin HW, Lee JM, Lee HW, Kim EC, Park SH. An overview of pathogen recognition receptors for innate immunity in dental pulp. Mediators Inflamm. (2015) 2015:794143. doi: 10.1155/2015/794143

43. Houdebine LM. Use of transgenic animals to improve human health and animal production. Reprod Domest Anim. (2005) 40:269-81. doi: 10.1111/j.1439-0531.2005.00596.x

44. Hall BE, Zhang L, Sun ZJ, Utreras E, Prochazkova M, Cho A, et al. Conditional TNF- $\alpha$ overexpression in the tooth and alveolar bone results in painful pulpitis and osteitis. J Dent Res. (2016) 95:188-95. doi: 10.1177/0022034515612022

45. Parson SH. Histology at a glance [Internet]. J Anatomy. (2011) 219:777. doi: 10.1111/j.1469-7580.2011.01434.x

46. Qi S, Qian J, Chen F, Zhou P, Yue J, Tang F, et al. Expression of autophagyassociated proteins in rat dental irreversible pulpitis. Mol Med Rep. (2019) 19:2749-57. doi: 10.3892/mmr.2019.9944

47. Eba H, Murasawa Y, Iohara K, Isogai Z, Nakamura H, Nakamura H, et al. The anti-inflammatory effects of matrix metalloproteinase- 3 on irreversible pulpitis of mature erupted teeth. Gullberg D, editor. PLoS ONE. (2012) 7:e52523. doi: 10.1371/journal.pone.0052523

48. Renard E, Gaudin A, Bienvenu G, Amiaud J, Farges JC, Cuturi MC, et al. Immune cells and molecular networks in experimentally induced pulpitis. J Dent Res. (2016) 95:196-205. doi: 10.1177/0022034515 612086

49. Okiji T, Morita I, Sunada I, Murota S. Involvement of arachidonic acid metabolites in increases in vascular permeability in experimental 
dental pulpal inflammation in the rat. Arch Oral Biol. (1989) 34:5238. doi: 10.1016/0003-9969(89)90090-3

50. Li JG, Lin JJ, Wang ZL, Cai WK, Wang PN, Jia Q, et al. Melatonin attenuates inflammation of acute pulpitis subjected to dental pulp injury. Am J Transl Res. (2015) 7:66-78.

51. Chattipakorn SC, Sigurdsson A, Light AR, Narhi M, Maixner W. Trigeminal c-Fos expression and behavioral responses to pulpal inflammation in ferrets. Pain. (2002) 99:61-9. doi: 10.1016/S0304-3959(02)00054-4

52. Songsiripradubboon S, Kladkaew S, Trairatvorakul C, Sangvanich P, Soontornvipart K, Banlunara W, et al. Stimulation of dentin regeneration by using acemannan in teeth with lipopolysaccharide-induced pulp inflammation. J Endod. (2017) 43:1097-103. doi: 10.1016/j.joen.2017.01.037

53. Moradi S, Bidar M, Zarrabi MH, Talati A. Dental pulp reaction to exposure at different time intervals in open apex canine teeth of cats. Iran Endod J. (2009) 4:49-52.

54. Meto A, Meto A, Tragaj E, Özcan M. Anti-inflammatory and regenerative effects of Albanian propolis in experimental vital amputations in piglets (Histological assessment). Int J Sci Res. (2016) 5:2041-5. doi: 10.21275/v5i7.ART2016664

55. Furseth R., Mjör, IA, Skogedal O. The fine structure of induced pulpitis in a monkey (Cercopithecus Aethiops). Arch Oral Biol. (1980) 24:883-8. doi: 10.1016/0003-9969(79)90213-9

56. Fuks AB, Jones PC, Michaeli Y, Bimstein E. Pulp response to collagen and glutaraldehyde in pulpotomized primary teeth of baboons. Pediatr Dent. (1991) 13:142-50.

57. Holsapple MP, West LJ, Landreth KS. Species comparison of anatomical and functional immune system development. Birth Defects Res Part B - Dev Reprod Toxicol. (2003) 68:321-34. doi: 10.1002/bdrb.10035

58. Loveless SE, Hoban D, Sykes G, Frame SR, Everds NE. Evaluation of the immune system in rats and mice administered linear ammonium perfluorooctanoate. Toxicol Sci. (2008) 105:86-96. doi: 10.1093/toxsci/kfn113

59. Pruett S, Hebert P, Lapointe J-M, Reagan W, Lawton M, Kawabata TT. Characterization of the action of drug-induced stress responses on the immune system: evaluation of biomarkers for drug-induced stress in rats. $J$ Immunotoxicol. (2007) 4:25-38. doi: 10.1080/15476910601115150

60. Mestas J, Hughes CC. Of mice and not men: differences between mouse and human immunology. J Immunol. (2004) 172:2731-8. doi: 10.4049/jimmunol.172.5.2731

61. Nakashima M, Iohara K, Bottino MC, Fouad AF, Nör JE, Huang GTJ. Animal models for stem cell-based pulp regeneration: foundation for human clinical applications. Tissue Eng - Part B Rev. (2019) 25:10013. doi: 10.1089/ten.teb.2018.0194

62. Perrone J. Small Animal Dental Procedures for Veterinary Technicians and Nurses. Chichester: Wiley (2012). p. 256.
63. Institute of Laboratory Animal Resources. Laboratory Animal Managment Dogs. Sage (1994). p. 152.

64. Felsburg PJ. Overview of immune system development in the dog: comparison with humans. Hum Exp Toxicol. (2002) 21:487-92. doi: 10.1191/0960327102ht286oa

65. Overgaard NH, Fan TM, Schachtschneider KM, Principe DR, Schook LB, Jungersen G. Of mice, dogs, pigs, and men: choosing the appropriate model for immuno-oncology research. ILAR J. (2018) 59:247-62. doi: 10.1093/ilar/ily014

66. Wang S, Liu Y, Fang D, Shi S. The miniature pig: a useful large animal model for dental and orofacial research. Oral Dis. (2007) 13:5307. doi: 10.1111/j.1601-0825.2006.01337.x

67. Humphray SJ, Scott CE, Clark R, Marron B, Bender C, Camm N, et al. A high utility integrated map of the pig genome. Genome Biol. (2007) 8:139. doi: 10.1186/gb-2007-8-7-r139

68. Dickson K, Lehmann C. Inflammatory response to different toxins in experimental sepsis models. Int J Mol Sci. (2019) 20:4341. doi: 10.3390/ijms20184341

69. Oliveira LA de, Barbosa SV. The reaction of dental pulp to Escherichia coli lipopolysaccharide and Enterococcus faecalis lipoteichoic acid. Brazilian J Microbiol. (2003) 34:179-81. doi: 10.1590/S1517-838220030002 00018

70. Hirsch V, Wolgin M, Mitronin AV, Kielbassa AM. Inflammatory cytokines in normal and irreversibly inflamed pulps: a systematic review. Arch Oral Biol. (2017) 82:38-46. doi: 10.1016/j.archoralbio.2017. 05.008

71. Ariji Y, Ariji E, Nakashima M, Iohara K. Magnetic resonance imaging in endodontics: a literature review. Oral Radiol. (2018) 34:10-6. doi: 10.1007/s11282-017-0301-0

72. Nardo D Di, Gambarini G, Capuani S, Testarelli L. Nuclear magnetic resonance imaging in endodontics: a review. J Endod. (2018) 44:53642. doi: 10.1016/j.joen.2018.01.001

Conflict of Interest: The authors declare that the research was conducted in the absence of any commercial or financial relationships that could be construed as a potential conflict of interest.

Copyright (c) 2021 Aubeux, Renard, Pérez, Tessier, Geoffroy and Gaudin. This is an open-access article distributed under the terms of the Creative Commons Attribution License (CC BY). The use, distribution or reproduction in other forums is permitted, provided the original author(s) and the copyright owner(s) are credited and that the original publication in this journal is cited, in accordance with accepted academic practice. No use, distribution or reproduction is permitted which does not comply with these terms. 